NASATM-2001-210396

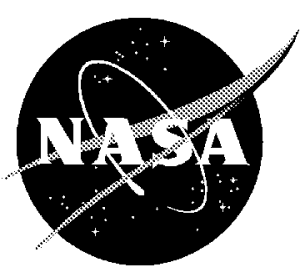

\title{
Reconfigurable Control Design for the Full X-33 Flight Envelope
}

M. Christopher Cotting and John J. Burken

NASA Dryden Flight Research Center

Edwards, California 


\section{The NASA STI Program Office...in Profile}

Since its founding, NASA has been dedicated to the advancement of aeronautics and space science. The NASA Scientific and Technical Information (STI) Program Office plays a key part in helping NASA maintain this important role.

The NASA STI Program Office is operated by Langley Research Center, the lead center for NASA's scientific and technical information. The NASA STI Program Office provides access to the NASA STI Database, the largest collection of aeronautical and space science STI in the world. The Program Office is also NASA's institutional mechanism for disseminating the results of its research and development activities. These results are published by NASA in the NASA STI Report Series, which includes the following report types:

- TECHNICAL PUBLICATION. Reports of completed research or a major significant phase of research that present the results of NASA programs and include extensive data or theoretical analysis. Includes compilations of significant scientific and technical data and information deemed to be of continuing reference value. NASA's counterpart of peer-reviewed formal professional papers but has less stringent limitations on manuscript length and extent of graphic presentations.

- TECHNICAL MEMORANDUM. Scientific and technical findings that are preliminary or of specialized interest, e.g., quick release reports, working papers, and bibliographies that contain minimal annotation. Does not contain extensive analysis.

- CONTRACTOR REPORT. Scientific and technical findings by NASA-sponsored contractors and grantees.
- CONFERENCE PUBLICATION.

Collected papers from scientific and technical conferences, symposia, seminars, or other meetings sponsored or cosponsored by NASA.

- SPECIAL PUBLICATION. Scientific, technical, or historical information from NASA programs, projects, and mission, often concerned with subjects having substantial public interest.

- TECHNICAL TRANSLATION. Englishlanguage translations of foreign scientific and technical material pertinent to NASA's mission.

Specialized services that complement the STI Program Office's diverse offerings include creating custom thesauri, building customized databases, organizing and publishing research results...even providing videos.

For more information about the NASA STI Program Office, see the following:

- Access the NASA STI Program Home Page at http://www.sti.nasa.gov

- E-mail your question via the Internet to help@sti.nasa.gov

- Fax your question to the NASA Access Help Desk at (301) 621-0134

- Telephone the NASA Access Help Desk at (301) 621-0390

- Write to: NASA Access Help Desk NASA Center for AeroSpace Information 7121 Standard Drive Hanover, MD 21076-1320 
NASA/TM-2001-210396

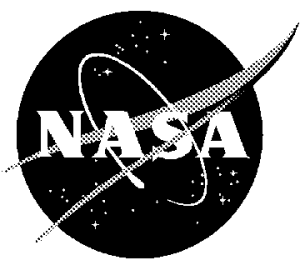

\section{Reconfigurable Control Design for the Full X-33 Flight Envelope}

M. Christopher Cotting and John J. Burken

NASA Dryden Flight Research Center

Edwards, California

National Aeronautics and

Space Administration

Dryden Flight Research Center

Edwards, California 93523-0273 


\section{NOTICE}

Use of trade names or names of manufacturers in this document does not constitute an official endorsement of such products or manufacturers, either expressed or implied, by the National Aeronautics and Space Administration.

Available from the following:

NASA Center for AeroSpace Information (CASI)

7121 Standard Drive

Hanover, MD 21076-1320

(301) 621-0390
National Technical Information Service (NTIS) 5285 Port Royal Road Springfield, VA 22161-2171 (703) $487-4650$ 


\title{
RECONFIGURABLE CONTROL DESIGN FOR THE FULL X-33 FLIGHT ENVELOPE
}

\author{
M. Christopher Cotting* and John J. Burken ${ }^{\dagger}$ \\ NASA Dryden Flight Research Center \\ Edwards, California
}

\begin{abstract}
$\underline{\text { Abstract }}$
A reconfigurable control law for the full X-33 flight envelope has been designed to accommodate a failed control surface and redistribute the control effort among the remaining working surfaces to retain satisfactory stability and performance. An offline nonlinear constrained optimization approach has been used for the $\mathrm{X}$-33 reconfigurable control design method. Using a nonlinear, six-degree-of-freedom simulation, three example failures are evaluated: ascent with a left body flap jammed at maximum deflection; entry with a right inboard elevon jammed at maximum deflection; and landing with a left rudder jammed at maximum deflection. Failure detection and identification are accomplished in the actuator controller. Failure response comparisons between the nominal control mixer and the reconfigurable control subsystem (mixer) show the benefits of reconfiguration. Single aerosurface jamming failures are considered. The cases evaluated are representative of the study conducted to prove the adequate and safe performance of the reconfigurable control mixer throughout the full flight envelope. The $\mathrm{X}$-33 flight control system incorporates reconfigurable flight control in the existing baseline system.
\end{abstract}

\section{Nomenclature}

$\begin{array}{ll}\text { BFGS } & \text { Broyden, Fletcher, Goldfarb and Shanno } \\ \text { EMA } & \text { electromechanical actuator } \\ \text { G } & \begin{array}{c}\text { Hessian inverse (maps differences in } \\ \text { position into differences in gradient) }\end{array}\end{array}$

\footnotetext{
*Aerospace Engineer, Member

$\dagger$ Aerospace Engineer, Member

Copyright $(2001$ by the American Institute of Aeronautics and Astronautics, Inc. No copyright is asserted in the United States under Title 17, U.S. Code. The U.S. Government has a royalty-free license to exercise all rights under the copyright claimed herein for Governmental purposes. All other rights are reserved by the copyright
} owner.

\begin{tabular}{|c|c|}
\hline $\mathrm{H}$ & Hessian matrix \\
\hline$k$ & iteration \\
\hline ONCO & offline nonlinear constrained optimization \\
\hline $\bar{q}$ & dynamic pressure, $\mathrm{lbf} / \mathrm{ft}^{2}$ \\
\hline Qalpha & $\begin{array}{l}\text { longitudinal aerodynamic loading } \\
\text { parameter, } \bar{q} * \alpha\end{array}$ \\
\hline Qbeta & $\begin{array}{l}\text { directional aerodynamic loading parameter, } \\
\qquad \bar{q} * \beta\end{array}$ \\
\hline $\mathrm{RCS}$ & reaction control system \\
\hline TAEM & terminal area energy management \\
\hline$x$ & tunable mixer gains \\
\hline $\mathbf{x}$ & vector \\
\hline$\alpha$ & angle of attack, deg \\
\hline$\beta$ & angle of sideslip, deg \\
\hline$\gamma$ & change in gradients \\
\hline$\delta$ & $\begin{array}{l}\text { difference between two points on quadratic } \\
\text { function }\end{array}$ \\
\hline$\nabla$ & first partial derivative or gradient vector \\
\hline
\end{tabular}

Aircraft flight control systems are designed with extensive redundancy to ensure sufficient failure mitigation. Hydraulically powered actuators have been used for the past 60 years and currently have a very low probability of failure. The X-33 vehicle (fig. 1), however, was designed to use one or more two-channel electromechanical actuators (EMAs) to power all the primary flight control surfaces.

The X-33 fault tree analysis indicates that EMAs are more likely to fail than hydraulic actuators; however, the advantages of using EMAs for vehicles like the X-33 vehicle outweigh the disadvantages. For example, power lines are easier to route than hydraulic lines, although 


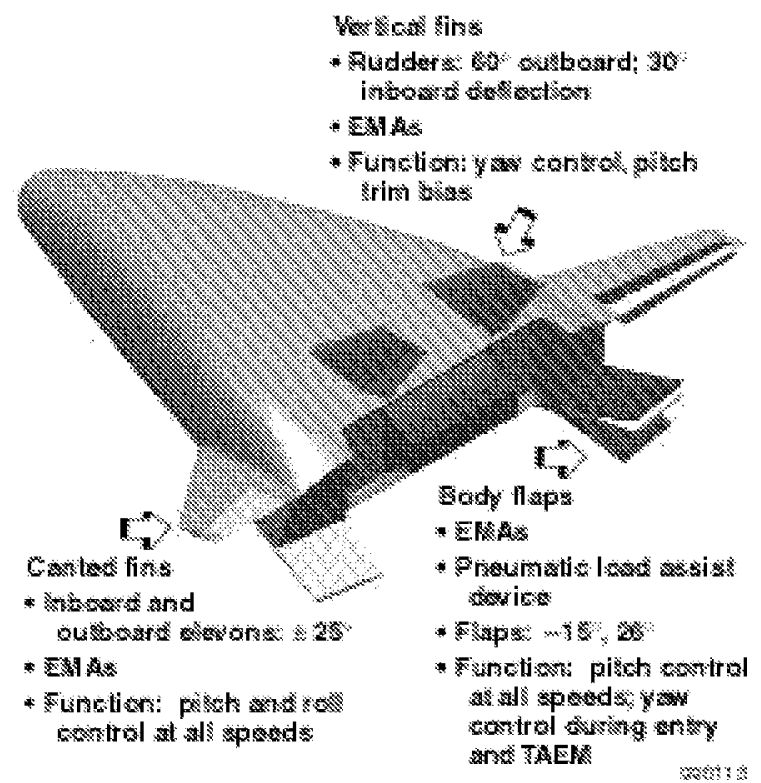

Figure 1. X-33 vehicle and aerosurfaces.

the weight is approximately the same. Analysis also has shown a few unlikely single-failure modes for the EMAs, failures that most likely would result in jamming of the associated aerosurface (the inability to move a control surface from a position).

The baseline X-33 flight control system contains control reconfiguration because the vehicle has low control effector redundancy compared to other aircraft. The primary motivation for pursuing reconfigurable control for this vehicle has been to improve use of functioning control effectors in the event of an effector failure. Because the EMAs are relatively unproven compared to modern hydromechanical actuators, the reconfigurable control mixer was designed to allow the vehicle to continue to operate in the event of an actuator failure. Although arguments could be made that this level of redundancy is not needed for an experimental aircraft, the $X-33$ vehicle would have been a technology demonstrator test bed to prove concepts for a subsequent single-stage-to-orbit, heavy-lift vehicle.

In designing the reconfigurable control system, control surface jamming failures were assumed in each of the eight aerosurfaces. Engine thrust vectoring and reaction control system (RCS) thrusters, which are part of the primary flight control system and enabled through the nominal control system mixer, are not part of the reconfigurable control system mixer and are not discussed.

Reference 1 presents results of four reconfigurable trade studies investigated on the X-33 entry flight phase (from Mach 9 decreasing to Mach 3) and concludes that an offline nonlinear constrained optimization (ONCO) method should be used for the reconfiguration method. Preliminary results of the offline method for portions of the flight envelope also have been published. ${ }^{1}$

This report investigates the full $\mathrm{X}-33$ flight envelope and details the nonlinear simulation results discovered in the final design of the reconfigurable flight control mixer for the X-33 vehicle. Three specific cases are evaluated in this report: a full-deflection body flap jamming failure during the ascent phase of flight, a full-deflection elevon jamming failure during the entry phase, and a full-deflection rudder jamming failure during the landing phase.

Note that use of trade names or names of manufacturers in this document does not constitute an official endorsement of such products or manufacturers, either expressed or implied, by the National Aeronautics and Space Administration.

\section{$\underline{\mathrm{X}-33 \text { Vehicle Description }}$}

The X-33 vehicle is a subscale, suborbital experimental vehicle designed to be a technology demonstrator for a single-stage-to-orbit, heavy-lift vehicle. The X-33 vehicle has four sets of aerosurfaces: rudders, body flaps, and inboard and outboard elevons (fig. 1). The X-33 vehicle was designed to use an aerospike engine, which allows for pitch and roll thrust vectoring as well as differential thrust yaw control. The $\mathrm{X}-33$ vehicle also was designed to use RCS thrusters for added vehicle control during unpowered flight.

\section{$\underline{\text { Nominal Control Description }}$}

Three major phases were to be encountered during the flight of the X-33 vehicle. The ascent phase would have begun at ignition of the main engines and continued until "main engine cutoff." This region of flight would have contained augmented control by engine thrust vectoring and would have been the only stable region of the flight envelope. Command during this phase of flight would have been accomplished using an Euler angle controller. Longitudinal and directional aerodynamic loading parameters were considered in control design to ensure structural integrity during this phase of flight.

After main engine cutoff, the entry phase of flight would have begun. This phase of flight would have exhibited the worst region of instability for the vehicle, especially in the low-angle-of-attack regions. The RCS would have been used for augmented control in areas of 
low dynamic pressure in this region of flight. Control during this phase would have been accomplished using an aerodynamic angle control scheme.

The terminal area energy management (TAEM) phase, also considered the landing phase, would have begun when the vehicle had slowed to Mach 3. This region of flight also would have exhibited areas of instability and been controlled by an acceleration command controller. The $\mathrm{X}-33$ vehicle was designed to use EMAs to power all the primary flight control surfaces. The X-33 vehicle also was designed to be controlled through a triplex fly-by-wire flight control system operating at 50 samples/sec.

Figure 2 shows a simulated nominal X-33 trajectory. The three flight phases are shown with ascent lasting $240 \mathrm{sec}$, entry lasting $260 \mathrm{sec}$, and TAEM lasting $265 \mathrm{sec}$. The vehicle reaches a maximum speed of Mach 9 and an altitude of 210,000 ft. Dynamic pressure changes from a maximum of $210 \mathrm{lbf} / \mathrm{ft}^{2}$ at $105 \mathrm{sec}$ to approximately $7 \mathrm{lbf} / \mathrm{ft}^{2}$ at $300 \mathrm{sec}$.

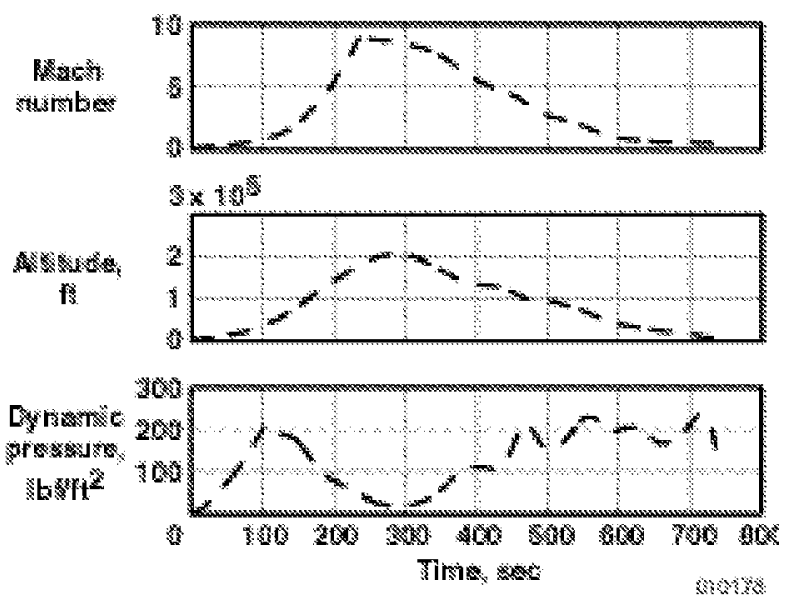

Figure 2. X-33 nominal trajectory.

\section{$\underline{\text { Reconfigurable Control Design }}$}

The four reconfigurable control design methods investigated for the X-33 vehicle were the redistributed pseudo-inverse; general constrained optimization; automated failure-dependent gain schedule; and the offline, or predefined, nonlinear constrained optimization methods. ${ }^{2}$ The ONCO approach was chosen for implementation. The ONCO method and preliminary results of this approach implemented in a six-degree-of-freedom simulation are discussed next and in reference 1 . The ONCO method was chosen because it could be easily tested and validated. The $\mathrm{X}-33$ vehicle has "smart actuators" that identify the surface that failed and the last known position of the failed surface. The failure could be a floating surface, a jammed surface, or a surface "hardover." Knowledge of the actuator state simplifies reconfiguration because fault detection and isolation is not needed as part of the primary flight controller.

\section{Offline Nonlinear Constrained Optimization}

With prior knowledge of the failure assumed, a table lookup of the failure to determine the controller changes meets the requirements of reconfiguration and is an approach that could be easily implemented. A table lookup of the gains has the added advantage of being easily tested in the validation and verification process required before the first vehicle flight. Therefore, an offline method of reconfiguration was decided to have the best chance of success for the X-33 flight program, and the ONCO method was chosen.

Figure 3 shows the control block diagram for the entry phase of X-33 flight. For this ONCO type of reconfiguration, the mixer is modified. Figures 4 and 5 show the nominal entry and reconfigurable mixers, respectively. The reconfigurable control mixer has more interconnect gains than the nominal control mixer. The roll command is sent to all the remaining actuators through a set of gains; whereas with the nominal mixer, the roll command is sent only to the elevons. The procedure of increasing interconnects was duplicated for the pitch and yaw commands. When a failure occurs, the nominal mixer is disabled and the reconfigurable mixer is brought online within $280 \mathrm{msec}$ of the failure. This procedure of using or changing the mixer to accommodate the failure is repeated for the ascent and TAEM control phases.

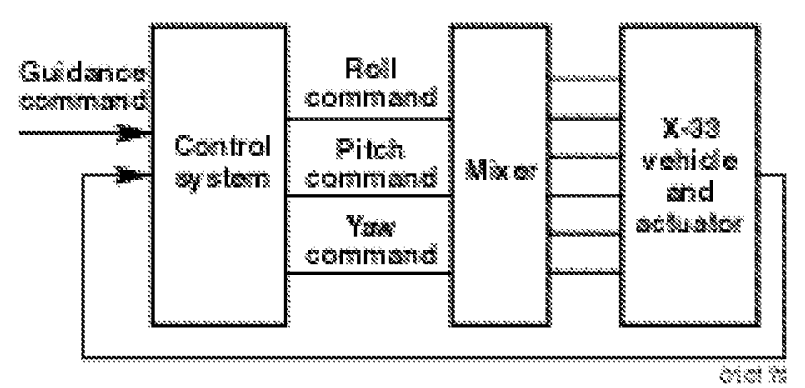

Figure 3. X-33 entry flight control. 


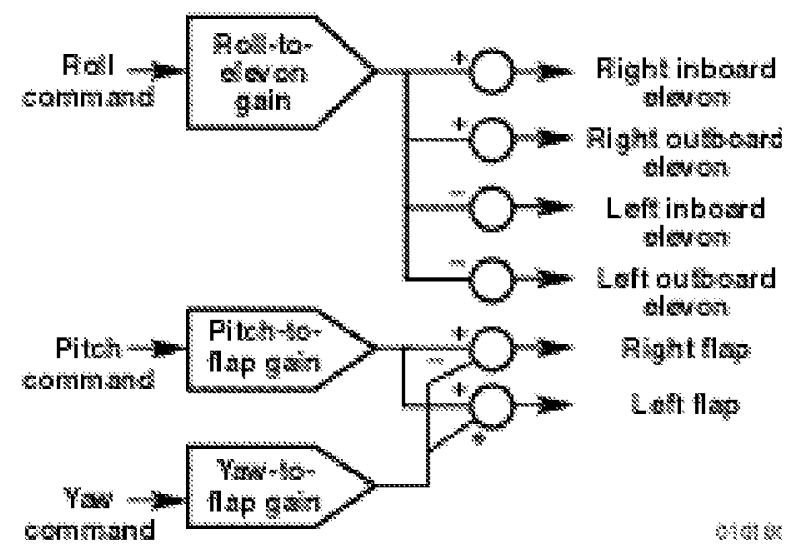

Figure 4. Nominal entry control mixer.

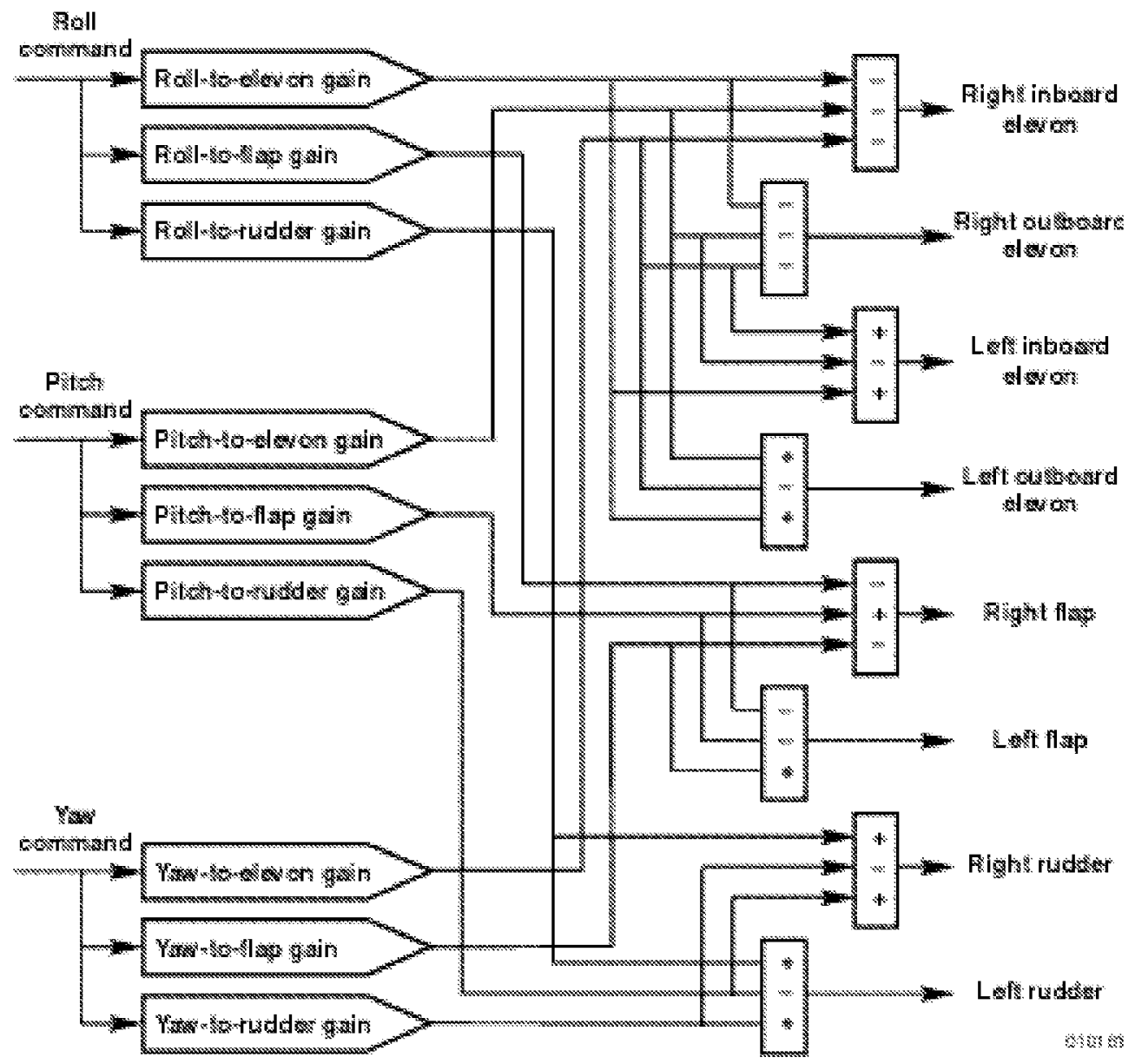

Figure 5. Reconfigurable control entry control mixer. 
The mixer gains were determined beforehand (offline) using a sequential quadratic programming method. This quasiNewton method is solved for each iteration of the quadratic programming problem and updates an estimate of the Hessian of the Lagrangian using a formula known as the BFGS formula because it was suggested by Broyden, Fletcher, Goldfarb and Shanno. ${ }^{3}$

Equation (1) shows the constrained nonlinear optimization:

$$
\text { Minimum }_{x} f(\mathbf{x}) \text { subject to } \mathrm{G}(\mathbf{x}) \leq 0
$$

If $f(\mathbf{x})$ is twice differentiable, then a matrix of second partial derivatives or Hessian matrix exists; where $x$ is the tunable mixer gains, and

$$
\mathrm{G}(\mathbf{x})=\nabla^{2} f(\mathbf{x})
$$

where $\mathrm{G}$ is a positive semidefinite matrix and $\mathrm{H} \approx \mathrm{G}^{-1}$. The $\left(\mathrm{G}^{(k)}\right)^{-1}$ is approximated by a symmetric positive definite matrix $\mathrm{H}^{(k)}$. The expression shown in equation (2) is sometimes called the quasiNewton condition. 3,4

$$
\mathrm{H}^{(k+1)} \gamma^{(k)}=\delta^{(k)}
$$

An important relationship suggested by Broyden, Fletcher, Goldfarb and Shanno is known as the BFGS formula: ${ }^{4}$

$$
\mathrm{H}_{\mathrm{BFGS}}^{(k+1)}=\mathrm{H}+\left(1+\frac{\gamma^{\mathrm{T}} \mathrm{H} \gamma}{\delta^{\mathrm{T}} \gamma}\right) \frac{\delta \delta^{\mathrm{T}}}{\delta^{\mathrm{T}} \gamma}-\left(\frac{\delta \gamma^{\mathrm{T}} \mathrm{H}+\mathrm{H} \gamma \delta^{\mathrm{T}}}{\delta^{\mathrm{T}} \gamma}\right)
$$

The ONCO method optimizes a time-domain response. Using equation (3) to constrain the timedomain errors and allowing the gains shown in figure 5 to be the tunable parameters (gains in the mixer), a series of closed-loop offline simulations are run. After a simulation run (usually a step-command response), the errors between the commanded and the actual response are summed and a new simulation trial is run with the modified gain set. The modified gain set is the result of using equation (3) to find a constrained optimal reduction in the summed error.

The simulation commands were a combination of roll and pitch steps in which the size of the roll command was $20^{\circ}$ and the size of the pitch command was $2^{\circ}$. The sizes of the roll and pitch commands were found to be large enough to stress the algorithm optimization. A stressed algorithm occurs when a control surface rate-limits or surface position saturates. At this condition, the control surface enters into a nonlinear region. Simultaneously executing a pitch and roll command was necessary to couple the dynamics.

Optimization based on the BFGS formula was found to work satisfactorily for the $\mathrm{X}-33$ reconfigurable control law design. The limitations of the sequential quadratic programming method are that the function to be minimized and the constraints must be continuous, and the method might give only local solutions. The controls tool package used for the reconfiguration development is a well-known control tool set. ${ }^{5}$ The interested reader is recommended to see the proportional, integral, differential demonstration included in nonlinear control design blockset for use with the Matlab ${ }^{\circledR}$ Simulink ${ }^{\circledR}$ (MathWorks Inc., Natick, Massachusetts) package. ${ }^{5}$

\section{Results and Conclusions Using a Nonlinear Simulation}

The initial mixer gains were implemented in a sixdegree-of-freedom simulation. During initial testing of the reconfigured mixer gains, some rate limiting and position saturation of the actuators were observed. The gains were determined to be too large because of differences between the linear models and the nonlinear simulation. Using empirical methods, the gains were reduced, which resulted in very good six-degree-offreedom results.

Later in the program, improved linear models were developed that very closely matched the nonlinear sixdegree-of-freedom simulation, so the gain reductions were not needed. Special attention to the linear models is extremely important in the design of the controller, especially in gain development. Examples are presented to show that control reconfiguration addresses three different failures in three different flight phases.

\section{$\underline{\text { Ascent Phase }}$}

The ascent controller is a Euler command tracking system. ${ }^{6}$ During the ascent phase, attitude control is provided by rocket engine thrust-vector control and the aerosurfaces. When a control surface is jammed, all the remaining operational control surfaces are used for control in conjunction with the thrust-vector control.

Figure 6(a) shows the response for the nominal and reconfigurable control systems of the vehicle with a worst-case hardover left body flap jamming at $25^{\circ}$ 
$20 \mathrm{sec}$ after lift-off. The time history shows the nominal controller with the failed surface held the pitch angle error to within $5^{\circ}$ in the longitudinal axis. With the reconfigurable controller, pitch angle error was reduced to $2^{\circ}$. Figure $6(\mathrm{~b})$ shows the lateral axis response to the left body flap failure. Bank angle was controlled to within $8^{\circ}$ with the nominal controller and to within $3^{\circ}$ with the reconfigurable control system.
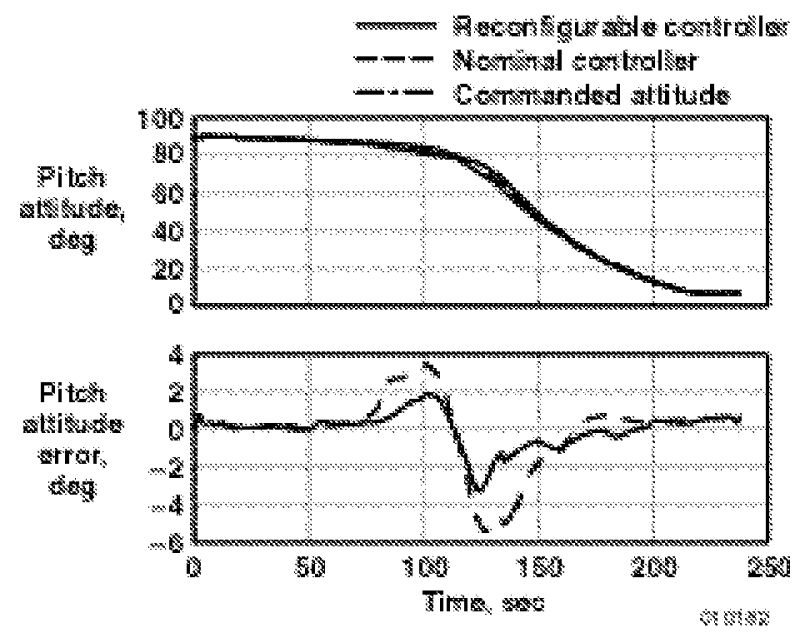

(a) Pitch attitude.
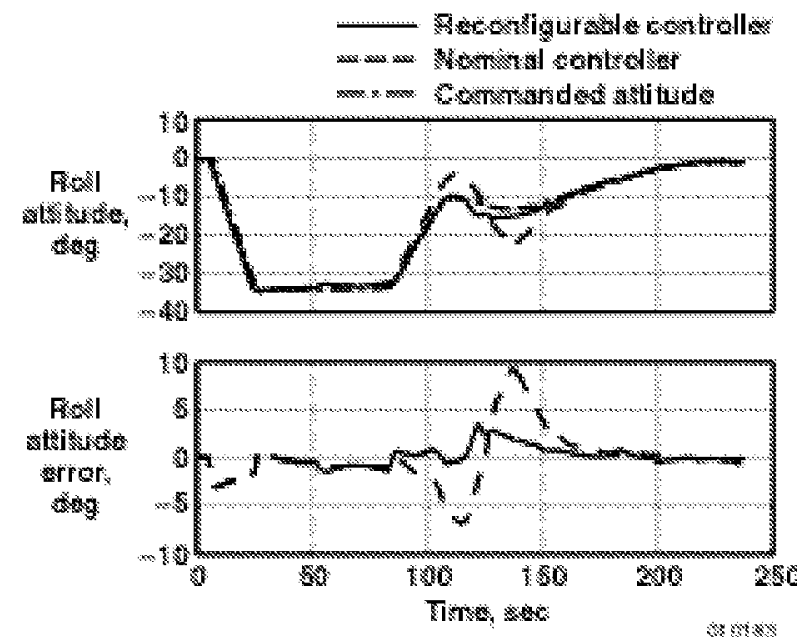

(b) Roll attitude.

During the ascent phase of flight, the aerodynamic loads on the aircraft must be kept to a minimum so that the structural integrity is not jeopardized. Two of the design parameters used for structural load minimization are the longitudinal and directional aerodynamic loading parameters, Qalpha and Qbeta. For the directional axis, if the angle of sideslip, $\beta$, is close to $0^{\circ}$, then the side loads (Qbeta) will not be a structural problem. Figure 6(c) shows times histories of Qalpha and Qbeta for the failed ascent case with both nominal and reconfigurable control mixers. The results show that a reduction in aerodynamic loads will occur if reconfigurable controls are used.

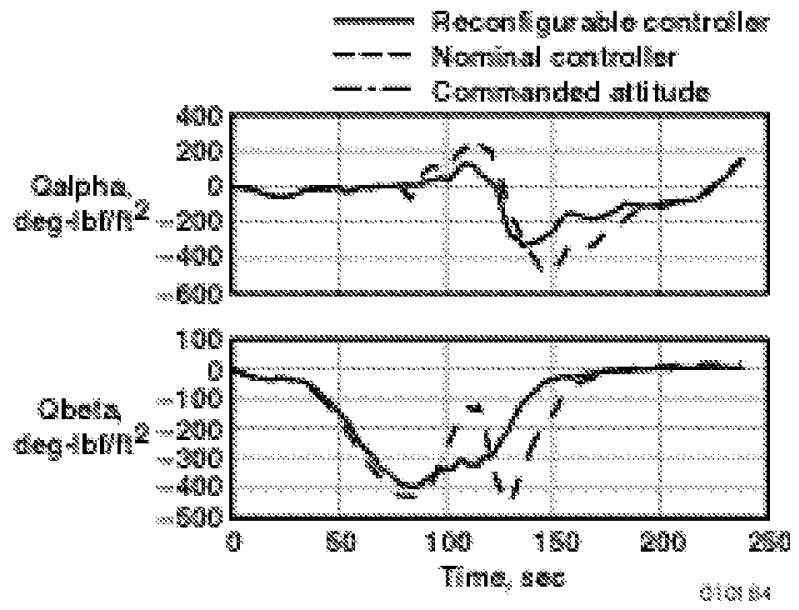

(c) Aero load indicator.

Figure 6. Ascent time responses.

Figure 6(d) shows plots of the control effectors (surface positions) from the nominal and reconfigurable mixer simulation flights. When the left body flap was jammed at $25^{\circ}$ (down), the nominal controller did fully compensate for this reaction using thrust vectoring available from the engine. The reconfigurable mixer, however, did result in lower Qalpha and Qbeta.

The body flaps are the most effective aerodynamic surfaces on the $\mathrm{X}-33$ vehicle but are the most difficult to reconfigure in the event of a failure. Overall ascent results show that the nominal controller can handle any aerosurface failure; however, the reconfigurable controller holds the vehicle closer to the desired flight trajectory.

\section{Entry Phase}

The entry controller is an angle-of-attack command tracking system for the longitudinal axis and a bank command system for the lateral axis. The entry control system has aerosurfaces and eight RCS jets (the thrust from each RCS jet is $500 \mathrm{lbf}$ ) for control effectors.

Approximately $10 \mathrm{sec}$ into the entry phase, the right inboard elevon was failed to $25^{\circ}$ (fig. 7(a)). A minor 


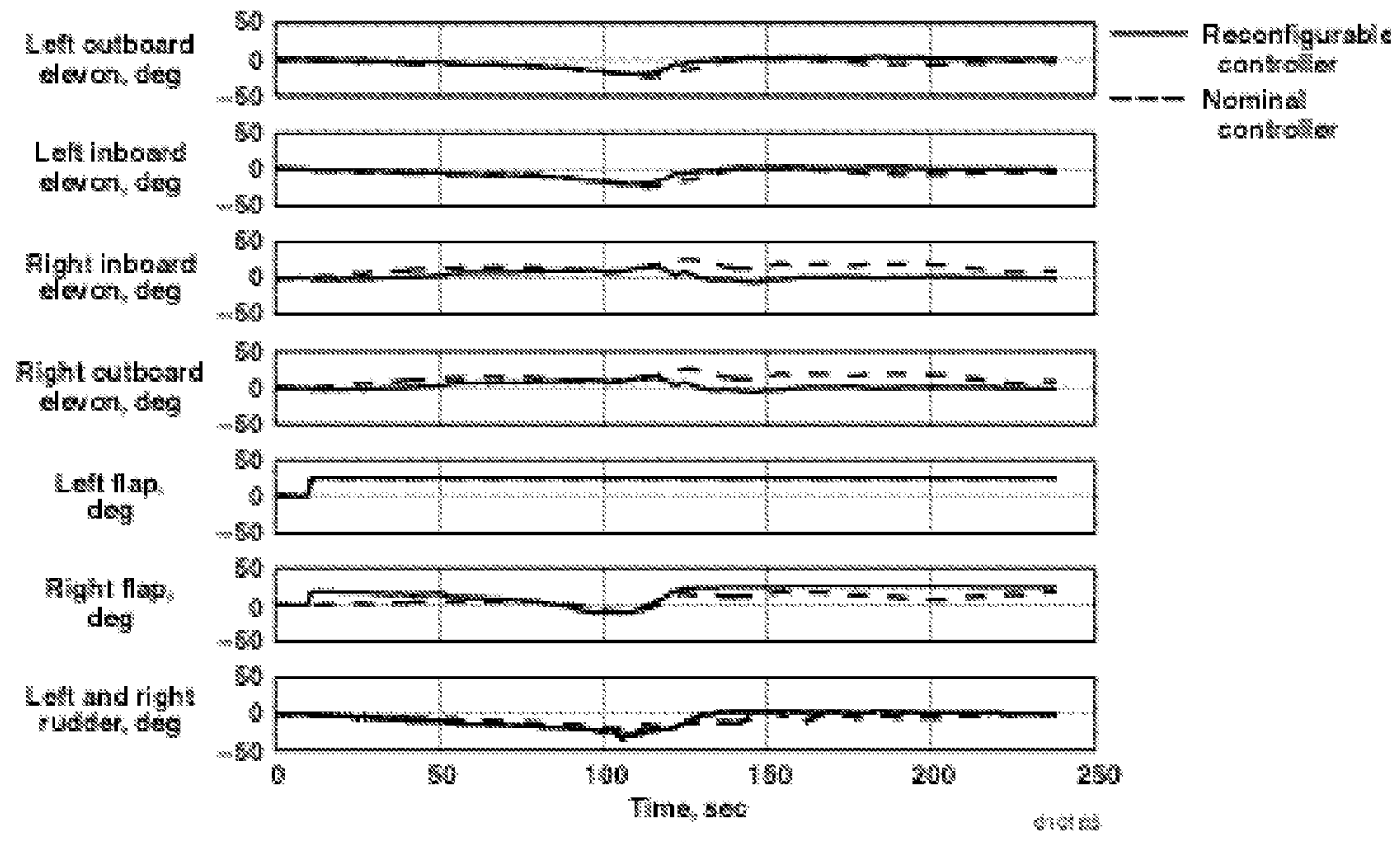

(d) Control surface.

Figure 6. Concluded.

transient appeared for this case because of the low value of dynamic pressure that was present at the time of failure. The nominal mixer maintained control of the vehicle for approximately $70 \mathrm{sec}$ before the vehicle departed in the lateral-directional axis (fig. 7(b)). A few seconds later, the vehicle also departed longitudinally. For the same failure, the reconfigured mixer was able to follow the commands for the entire entry flight phase.
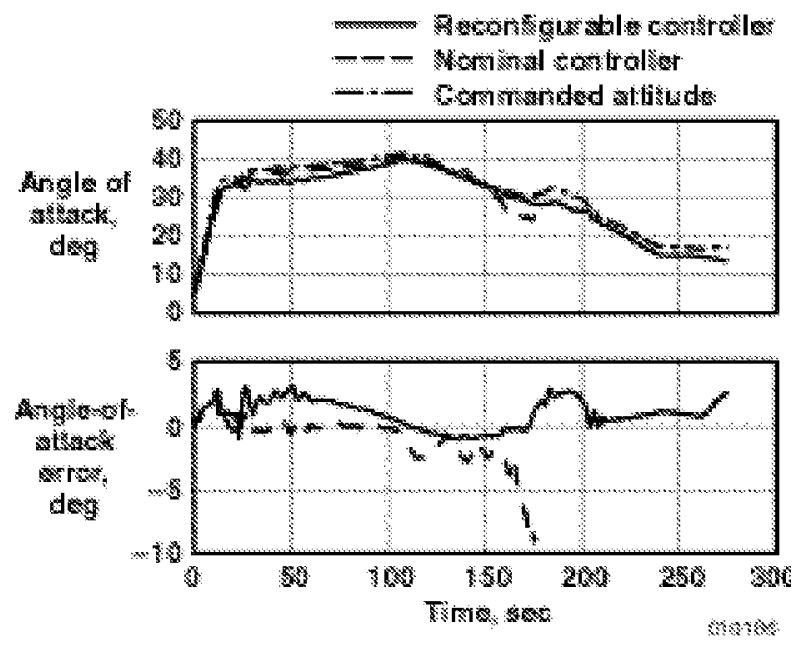

(a) Angle of attack.

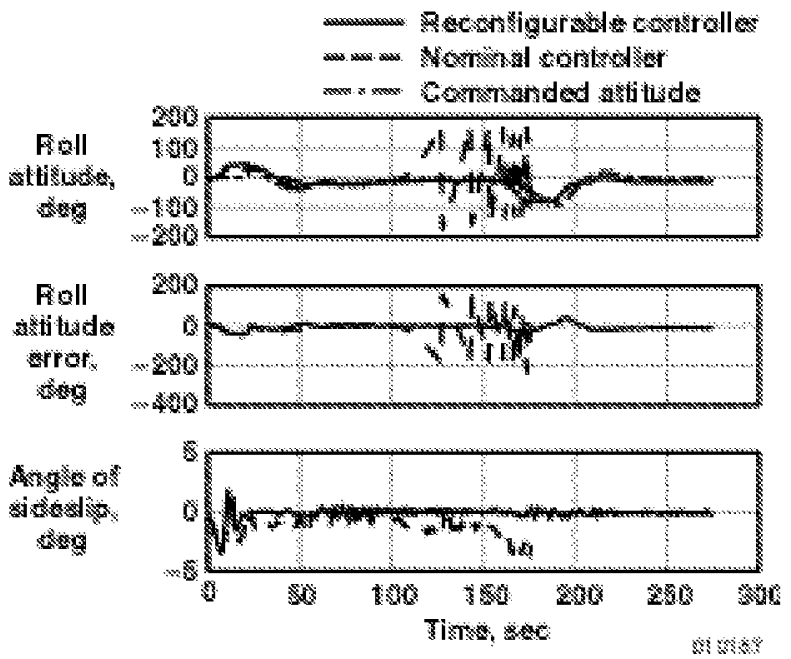

(b) Lateral-directional.

Figure 7. Entry time responses.

Figure 7(c) shows plots of the control effectors (surface positions) from the two simulated flights. When the right inboard elevon was jammed at $25^{\circ}$ (down), the left inboard nominal controller did not fully compensate for this reaction; and as a result, the vehicle departed. The departure was not immediate because of nominal controller compensation with RCS control effectors. 


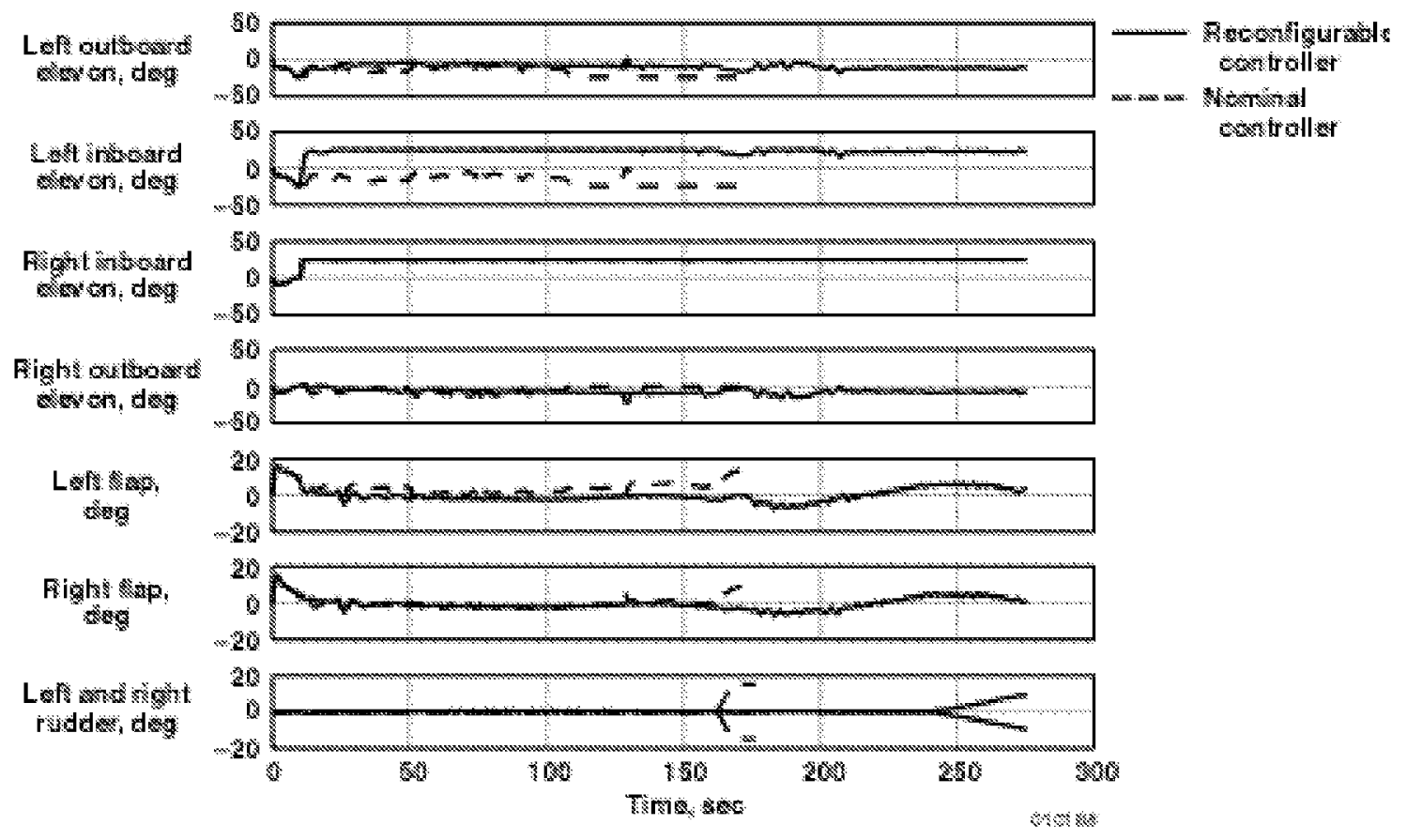

(c) Control surface.

Figure 7. Concluded.

However, figure 6(c) also shows the reconfigurable controller compensated for the right inboard elevon jamming by commanding the left inboard elevon to $23^{\circ}$.

The reconfigurable controller uses elevons, flaps, and rudders to control the vehicle and achieve the desired tracking commands from guidance. As figure 7 shows, reconfigurable controls allow the vehicle to continue on the desired trajectory to a safe entry conclusion (Mach 3).

\section{Terminal Area Energy Management Phase}

The TAEM phase controller has a normal acceleration command system for the longitudinal axis and a bank command system for the lateral axis. The TAEM control system uses aerosurfaces and RCS jets until the vehicle reaches a speed of Mach 2.

Approximately $20 \mathrm{sec}$ into the TAEM flight phase, the left rudder was jammed at $-30^{\circ}$ (trailing-edge right). A rudder failure was chosen for this case because of the "heading alignment cone" maneuver that was performed during this phase and the corresponding turn coordination difficulties encountered with a 270-deg turn.
Figure 8(a) shows the nominal TAEM controller normal acceleration and angle-of-attack time histories depart before $40 \mathrm{sec}$ have elapsed. The corresponding lateral axis results present a departure in $\beta$ at $50 \mathrm{sec}$ for the nominal controller (fig. 8(b)). Figure 8(c) shows the longitudinal and lateral ground track. The nominal controller cannot execute the turn. The reconfigurable controller, however, continues down to a survivable landing.

The reconfigurable controller executed a successful landing with a sink rate of $7 \mathrm{ft} / \mathrm{sec}$ (fig. $7(\mathrm{c})$ ). Desired sink rate landing criterion for this vehicle is $5 \mathrm{ft} / \mathrm{sec}$, with an acceptable sink rate not to exceed $10 \mathrm{ft} / \mathrm{sec}$. Although landing performance was not desired, it did fall within acceptable parameters; and unlike the nominal controller, it did allow the aircraft to land safely with an aerodynamic surface failure.

Figure 8(d) shows plots of the control effectors (surface positions) from the nominal and reconfigurable mixer simulation flights. When the left rudder was jammed at $-30^{\circ}$ (right), the nominal controller did not fully compensate for this reaction. The reconfigurable controller did allow for a landing of the vehicle within acceptable parameters. 


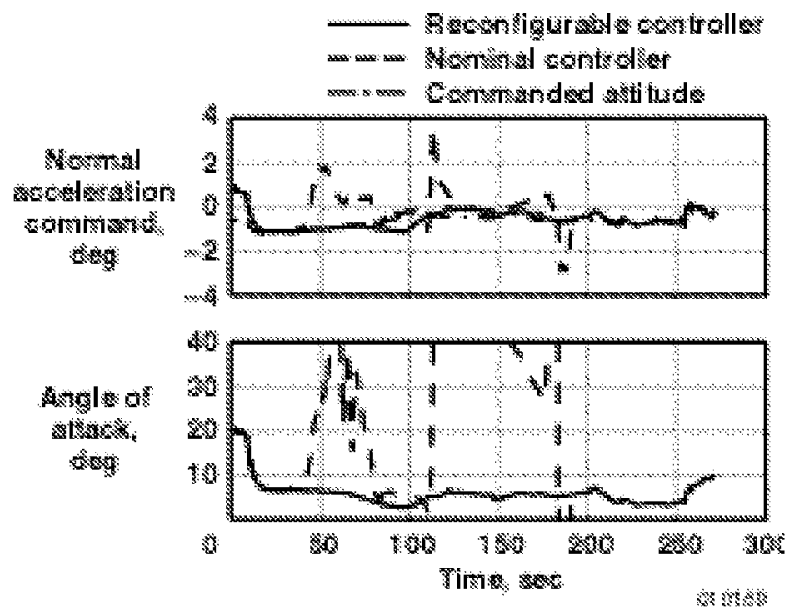

(a) Normal acceleration and angle of attack.

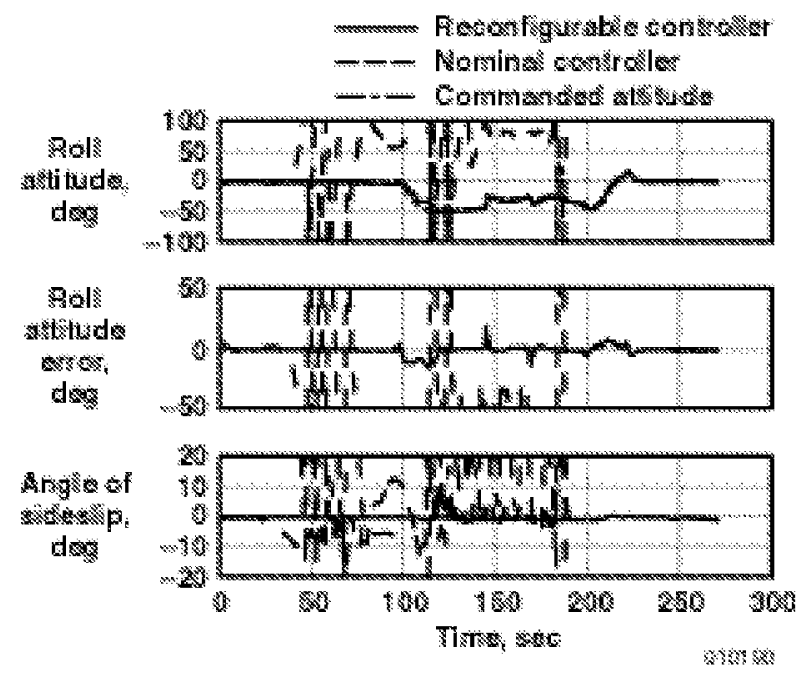

(b) Lateral-directional.
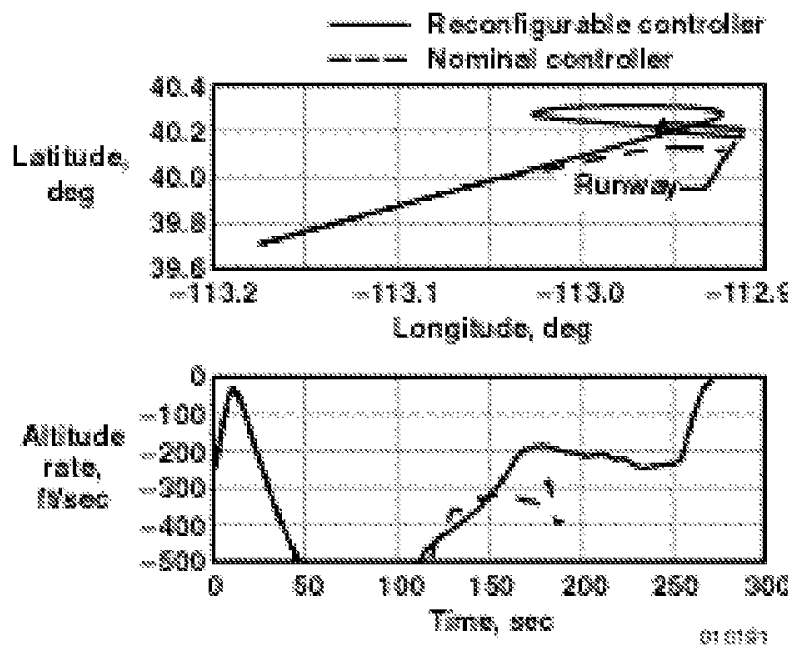

(c) Landing criteria.

Figure 8. TAEM time responses. 


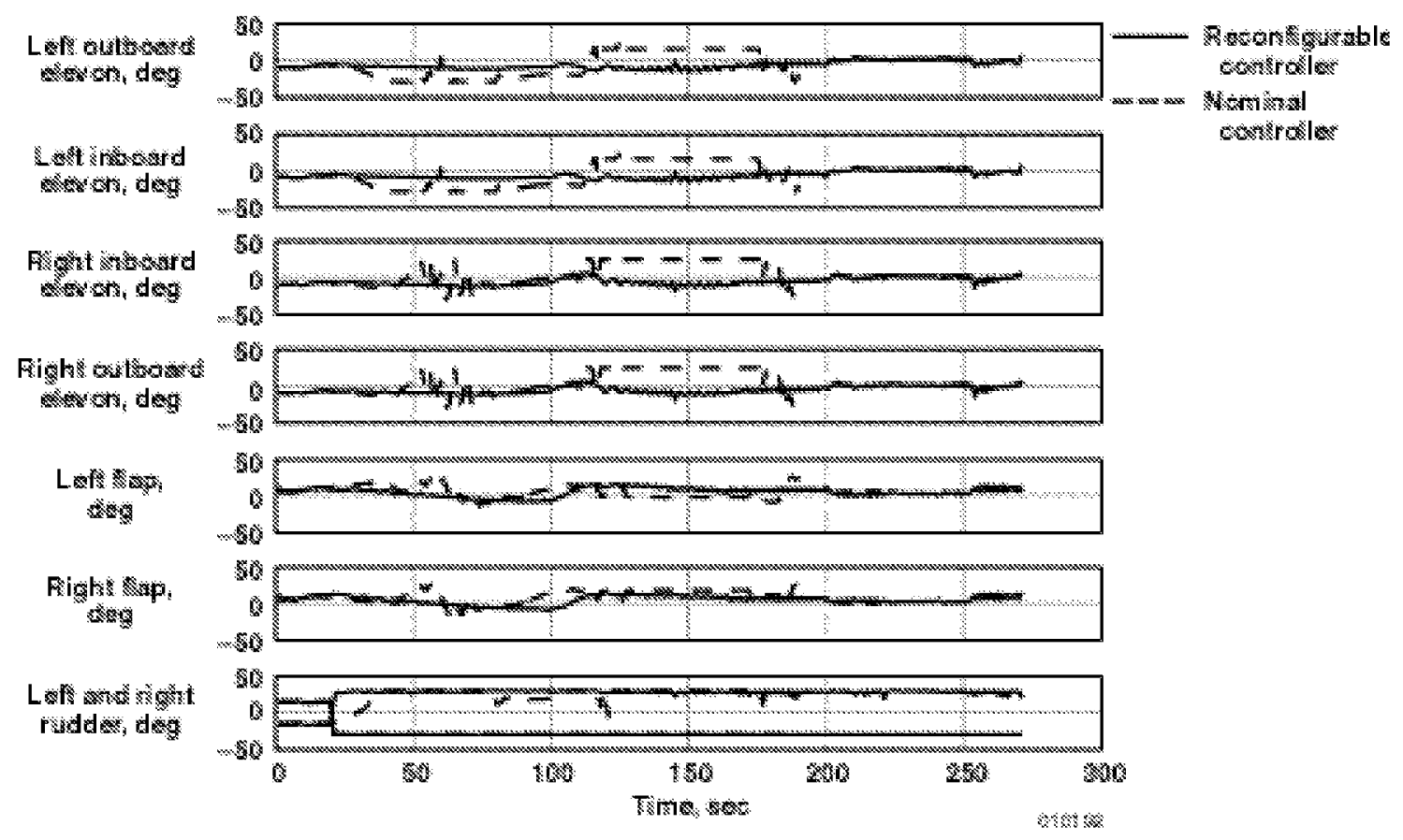

(d) Control surface.

Figure 8. Concluded.

\section{Full Flight Envelope Results}

During the ascent phase, the nominal and reconfigurable controller worked well. The reconfigurable controller had lower aerodynamic loads than the nominal controller during ascent. Table 1 shows the X-33 failure accommodation. The ascent reconfigurable phase was successful for all surface failures at speeds from Mach 0 to Mach 9. The entry phase, however, had a different outcome. The reconfigurable controller could handle all elevon failures for all Mach numbers. The body flap was the limiting factor in the entry phase of flight. The reconfigurable controller could handle only body flap jams between $-3^{\circ}$ and $5^{\circ}$ and a limited range from Mach 3 to Mach 5.2. The rudders were fully reconfigurable for the entire entry envelope. The TAEM phase also was limited in scope. The elevons and rudders could fail at any position during TAEM and land safely. The body flap, however, was limited from $-3^{\circ}$ to $5^{\circ}$.

Table 1. X-33 surface failure accommodation.

\begin{tabular}{|c|c|c|c|}
\hline \multirow[b]{2}{*}{ Surface } & \multicolumn{3}{|c|}{ Phase } \\
\hline & Ascent & Entry & TAEM \\
\hline Elevons & $\begin{array}{l}\text { All Mach numbers (Mach 0-9); } \\
\text { all surface positions }\end{array}$ & $\begin{array}{l}\text { All Mach numbers (Mach 9-3); } \\
\text { all surface positions }\end{array}$ & $\begin{array}{l}\text { All Mach numbers (Mach 3-0); } \\
\text { all surface positions }\end{array}$ \\
\hline Body flap & $\begin{array}{l}\text { All Mach numbers (Mach 0-9); } \\
\text { all surface positions }\end{array}$ & $\begin{array}{l}\text { Limited surface positions; } \\
\text { Mach } 3.0-5.2 \\
\text { flap deflection }-3^{\circ}-5^{\circ}\end{array}$ & $\begin{array}{l}\text { Limited surface positions; } \\
\text { Mach } 0-2.5 \\
\text { flap deflection }-3^{\circ}-5^{\circ}\end{array}$ \\
\hline Rudders & $\begin{array}{l}\text { All Mach numbers (Mach 0-9); } \\
\text { all surface positions }\end{array}$ & $\begin{array}{l}\text { All Mach numbers (Mach 9-3); } \\
\text { all surface positions }\end{array}$ & $\begin{array}{l}\text { All Mach numbers (Mach 3-0); } \\
\text { all surface positions }\end{array}$ \\
\hline
\end{tabular}




\section{$\underline{\text { Concluding Remarks }}$}

A reconfigurable control system was designed and implemented in a nonlinear, six-degree-of-freedom simulation for the X-33 vehicle. After significant testing, this system was determined to be a viable option to improve reliability concerns about a new actuator subsystem for the vehicle. Because of these concerns with the actuator subsystem, the reconfiguration design scope was limited to only control surface failures. The offline nonlinear constrained optimization approach was shown to be an adequate design methodology after testing this algorithm with many failure scenarios. The three failure examples presented (a left body flap during ascent, an inboard elevon during entry, and a rudder during landing) are examples from a much larger test matrix conducted to prove system viability. The overall design effort showed that certain control failures were much easier to accommodate than others.

Based on the results of the fully nonlinear simulator work, the project determined that the control reconfiguration system should be included onboard the $\mathrm{X}-33$ vehicle. The $\mathrm{X}-33$ vehicle would have been the first non-controls-research vehicle to incorporate reconfigurable flight control in the baseline control system.

\section{$\underline{\text { References }}$}

${ }^{1}$ Wagner, Elaine A., John J. Burken, Curtis E. Hanson, and Jerry M. Wohletz, "Deterministic Reconfigurable Control Design For the X-33 Vehicle," AIAA-98-4413, Aug. 1999.

${ }^{2}$ Virnig, John C. and David S. Bodden, "Multivariable Control Allocation and Control Law Conditioning When Control Effectors Limit," AIAA-94-3609, Aug. 1994.

${ }^{3}$ Fletcher, R. and M. J. D. Powell, "A Rapidly Convergent Descent Method for Minimization," The Complete Journal, vol. 6, no. 2, July 1963, pp. 163-168.

${ }^{4}$ Fletcher, R., Practical Methods of Optimization: Volume 1, Unconstrained Optimization, John Wiley \& Sons, Chichester, 1980.

${ }^{5}$ Nonlinear Control Design Blockset, The MathWorks Inc., Natick, Mass., 1997.

${ }^{6}$ Hall, Charles E., Michael W. Gallaher, Neal E. Hendrix, "X-33 Attitude Control System Design for Ascent, Transition, and Entry Flight Regimes," AIAA-98-4411, Aug. 1998. 
Public reporting burden for this collection of information is estimated to average 1 hour per response, including the time for reviewing instructions, searching existing data sources, gathering and maintaining the data needed, and completing and reviewing the collection of information. Send comments regarding this burden estimate or any other aspect of this collection of information, including suggestions for reducing this burden, to Washington Headquarters Services, Directorate for Information Operations and Reports, 1215 Jefferson Davis Highway, Suite 1204, Arlington, VA 22202-4302, and to the Office of Management and Budget, Paperwork Reduction Project (0704-0188), Washington, DC 20503.

\begin{tabular}{|l|l|}
\hline 1. AGENCY USE ONLY (Leave blank) & 2. REPORT DATE
\end{tabular} August 2001

\section{REPORT TYPE AND DATES COVERED} Technical Memorandum

4. TITLE AND SUBTITLE

Reconfigurable Control Design for the Full X-33 Flight Envelope 6. AUTHOR(S)

WU 715-33-02-E8-23-00-T19

M. Christopher Cotting and John J. Burken

7. PERFORMING ORGANIZATION NAME(S) AND ADDRESS(ES)

8. PERFORMING ORGANIZATION REPORT NUMBER

NASA Dryden Flight Research Center

P.O. Box 273

Edwards, California 93523-0273

H-2458

9. SPONSORING/MONITORING AGENCY NAME(S) AND ADDRESS(ES)

10. SPONSORING/MONITORING AGENCY REPORT NUMBER

National Aeronautics and Space Administration

Washington, DC 20546-0001

NASA/TM-2001-210396

\section{SUPPLEMENTARY NOTES}

Presented at AIAA Guidance, Navigation \& Control Conference, Montreal, Quebec, Canada, August 6-10, 2001, AIAA-2001-4379.

12a. DISTRIBUTION/AVAILABILITY STATEMENT 12b. DISTRIBUTION CODE

Unclassified-Unlimited

Subject Category 08

This report is available at http://www.dfrc.nasa.gov/DTRS/

13. ABSTRACT (Maximum 200 words)

A reconfigurable control law for the full X-33 flight envelope has been designed to accommodate a failed control surface and redistribute the control effort among the remaining working surfaces to retain satisfactory stability and performance. An offline nonlinear constrained optimization approach has been used for the X-33 reconfigurable control design method. Using a nonlinear, six-degree-of-freedom simulation, three example failures are evaluated: ascent with a left body flap jammed at maximum deflection; entry with a right inboard elevon jammed at maximum deflection; and landing with a left rudder jammed at maximum deflection. Failure detection and identification are accomplished in the actuator controller. Failure response comparisons between the nominal control mixer and the reconfigurable control subsystem (mixer) show the benefits of reconfiguration. Single aerosurface jamming failures are considered. The cases evaluated are representative of the study conducted to prove the adequate and safe performance of the reconfigurable control mixer throughout the full flight envelope. The X-33 flight control system incorporates reconfigurable flight control in the existing baseline system.

Control System Reconfiguration, Emergency Backup System, Reusable Launch

Vehicles, X-33 Flight Control

17. SECURITY CLASSIFICATION

OF REPORT

Unclassified

\begin{tabular}{|l|l}
\hline $\begin{array}{l}\text { 18. SECURITY CLASSIFICATION } \\
\text { OF THIS PAGE }\end{array}$ & $\begin{array}{c}\text { 19. SECURITY CLASSIFICATION } \\
\text { OF ABSTRACT } \\
\text { Unclassified }\end{array}$ \\
Unclassified \\
\hline
\end{tabular}

18. SECURITY CLASSIFICATION

Unclassified
15. NUMBER OF PAGES

11

16. PRICE CODE

$\mathrm{A} 03$

20. LIMITATION OF ABSTRACT

Unlimited 